University of Nebraska - Lincoln

DigitalCommons@University of Nebraska - Lincoln

2006

Intercontinental biotic invasions: what can we learn from native populations and habitats?

\author{
Qinfeng Guo \\ USGS Northern Prairie Wildlife Research Center
}

Follow this and additional works at: https://digitalcommons.unl.edu/usgsnpwrc

Part of the Other International and Area Studies Commons

Guo, Qinfeng, "Intercontinental biotic invasions: what can we learn from native populations and habitats?" (2006). USGS Northern Prairie Wildlife Research Center. 19.

https://digitalcommons.unl.edu/usgsnpwrc/19

This Article is brought to you for free and open access by the US Geological Survey at DigitalCommons@University of Nebraska - Lincoln. It has been accepted for inclusion in USGS Northern Prairie Wildlife Research Center by an authorized administrator of DigitalCommons@University of Nebraska - Lincoln. 
Biological Invasions (2006) 8:1451-1459

DOI $10.1007 / \mathrm{s} 10530-005-5834-1$

\title{
Intercontinental biotic invasions: what can we learn from native populations and habitats?
}

\author{
Qinfeng Guo \\ U.S. Geological Survey, Northern Prairie Wildlife Research Center, 8711 37th St. SE, Jamestown, 58401, \\ ND, USA; (e-mail: qguo@usgs.gov; fax: +1-701-253-5553)
}

Key words: comparative methods, invasive species, native vs. exotic populations and habitats neo-disjunctions, trans-Pacific biotic invasions

\begin{abstract}
The effectiveness of management strategies for invasive species is often hampered by a lack of clear understanding of the factors that limit species distributions. The distribution of exotic species, especially those that are invasive, are often so dynamic that limiting factors are difficult to identify. Comparisons of exotic species between their native ranges, where they are presumably close to equilibrium with controlling factors, and their ranges in areas of introduction can circumvent this difficulty. Such studies would help identify (1) limiting factors for distributions in native ranges, (2) factors associated with a high degree of invasiveness, (3) changes in genetics and morphology since introduction, which also might contribute to invasiveness, and (4) future directions and rates of invasion as a basis for developing detection/warning systems. Findings from such comparative studies would be highly valuable for understanding the dynamics of biological invasions and for improving the effectiveness of management to prevent or control invasives.
\end{abstract}

\section{Introduction}

Why most invasive species are not invasive in their native habitats has puzzled scientists and land managers for decades. Although several related hypotheses (e.g., enemy release) have been proposed, there is no consensus among ecologists regarding the causes of invasion success. Efforts so far to understand the causes and potential controlling factors in biotic invasions have focused primarily on areas of introduction (Hierro et al. 2005) rather than native ranges, except for searching bio-control agents for a few species. The results from further research in the native habitats could, however, provide valuable information for expanding management efforts in the invaded ranges. For example, since the boundaries of native ranges are relatively stable, limiting factors might be easier to identify than they are in introduced regions where the ranges of invaders continue to expand. Information on abiotic limiting factors in native ranges can help us to predict areas and habitats into which invasive species might expand and the information on biotic limiting factors can help us to identify or select species that could compete with, or resist competition from (e.g., through allelochemicals) invasive species, especially during restoration processes and reserve establishment.

Many episodes of extensive biotic interchange among continents have been identified in geological history (Vermeij 1991), but perhaps none of them is comparable to the human-caused species exchanges in terms of scale (distance and the number of species) and rate. Among intercontinental species exchanges, trans-Pacific invasives provide a unique opportunity to address the challenging 
questions posed by introduced species (Guo 2002). Eastern Asia and North America have close floristic affinities and share more than 100 genera of plants with disjunct (discontinuous) distributions (Ricklefs and Latham 1992; Guo and Ricklefs 2000; Qian and Ricklefs 2004). Similar to the classic paleo-disjuncts formed millions of years ago, human-induced species exchanges between eastern Asia and North America form a new class of disjunctions, which I refer to as "neo-disjuncts". Other major intercontinental species exchanges by humans include: Europe to North America, and Central or South America to eastern Asia or Southeast Asia. The formation of these neo-disjuncts has been regarded as one of the most globally influential biogeographical processes in modern times.

Exotics or invasives introduced to others areas within the same continent (e.g., Spartina alterniflora, native to eastern North America but introduced in California) may already have had considerable time or opportunity to encounter or explore conditions favorable to them outside their native ranges. In contrast, some newcomers from far more remote regions or continents (e.g., transPacific and trans-Atlantic) might have greater potential to quickly spread, become dominant, and replace native plants in the totally new environments. It is also possible that the qualities that make species successful invaders might make them successful invaders when introduced back into their "native" ranges after substantial evolutionary modification in the introduced range.

Although it is crucial to evaluate the effects of invasive species on local ecosystems (e.g., di Castri 1989; Simberloff and Von Holle 1999), it is equally critical to better understand the invasives in their native habitats (e.g., performance, ecosystem functions), especially for management purposes. Here I address several issues related to a central question in intercontinental biotic invasions: why most invasive species are not invasive in their native habitats. I also address the importance of comparative approach and methodology issues in predicting the species that may become invasive after introduction and in tracing the source population and invasion pathways, with special emphasis on invasive plants. I specifically emphasize two questions: (1) what are the limiting factors in the invasives' native habitats that are overcome in areas of introduction (e.g., rapid adaptation to novel environments, pre-existing suitable environments, enemy release/release from natural enemies/competitors), and (2) how have these species changed since their introduction to new habitats (e.g., in genetics, morphology; see Bøhn et al. 2004).

\section{Synthesis of previous intercontinental comparisons}

As mentioned earlier, most studies on invasive species have been conducted in their introduced ranges, with special emphasis on their effects on local species or habitats (e.g., Livdahl and Willey 1991; Rhymer and Simberloff 1996; Mack et al. 2000; Sher and Marshall 2003). In such cases, the ecology and genetics of the focal species are often understood more fully in the introduced ranges than in their native ranges (e.g., Thebaud and Simberloff 2000). However, unlike many other local and regional ecological issues and processes, biological invasions implicitly involve both native and exotic populations and habitats. Information from native populations and habitats are critical for investigating the causes of species invasiveness and for developing control measures. Thus, a comparative approach is appropriate and potentially a powerful tool (Guo 2002).

Early comparative studies on invasive species have addressed a variety of issues: (1) their interactions (competition, predation, mutualism) with neighboring species (congeneric and heterogeneric species) in both native and invaded habitats (e.g., Blossey and Nötzold 1995; Memmott et al. 2000; Biggins and Kosoy 2001; Siemann and Rogers 2001); (2) genetic shifts following introduction (Rejmánek et al. 1991; Hänfling and Kollmann 2002; and many citations in Cox 2004); (3) phenology (e.g., Kowarik 1995); (4) ecological roles in local communities (Klironomos 2002); (5) abundance, frequency, and dominance (Klironomos 2002); (6) natural enemies (Torchin et al. 2001; Mitchell and Power 2003); (7) allelopathy (Callaway and Aschehoug 2000); (8) consumer effects (Moron and Vilá 2001); and (9) distribution and limiting factors (Kitayama and Mueller-Dombois 1995).

Collectively, these studies show that successful invasive species often have high genetic variability due to multiple introductions, phenotypic 
plasticity, well-developed dispersal capacities, and wide distributions across their native landscape (e.g., Lodge 1993; Pappert et al. 2000; Losos et al. 2001). These results suggest that changes in population and genetic structure from native to exotic habitats can shed light on the causes of invasiveness. However, although there is an increasing trend of comparative studies on invasives in their native and introduced ranges, those simultaneously evaluating multiple factors in one study are rare. The main drawback of a singlefactor approach is the potential for missing other causal factors because invasiveness likely depends on many factors and their interactions. Also, comparative studies have not produced a general consensus with respect to the importance of various factors influencing species invasiveness or distribution. For example, while higher genetic variation in exotic range is a significant factor for the invasiveness of many plant species (adaptation to new environments; Figure 1), reduced genetic variation also has been cited as the cause of high invasiveness (e.g., Argentine ants; Tsutsui et al. 2000).

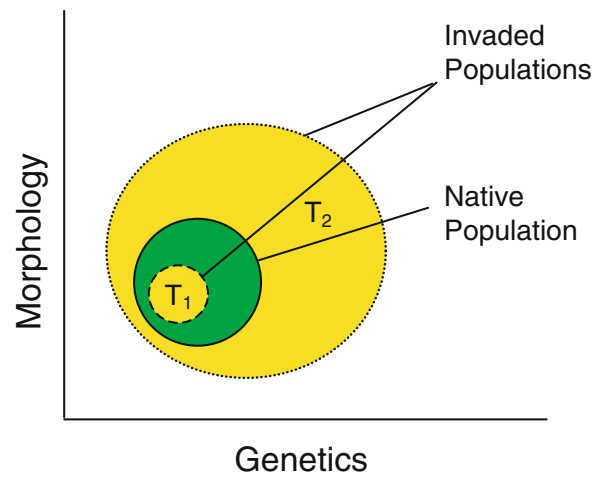

Figure 1. Hypothetical genetic, morphological, or ecological variations of invasives in multivariate space in their native vs. introduced ranges. Exotics initially $\left(\mathrm{T}_{1}\right)$ have less genetic or morphological variation than native populations due to "founder effect"(Cox 2004). Most exotic species may not go beyond this point (i.e., either they go extinct or become established with low invasiveness; Figure 2). In time, however, some exotics break though the "bottle-necking" and become invasive $\left(T_{2}\right)$ when both genetic and morphological variations (acquired after arrival) are higher than native populations. This is particularly the case with multiple introductions to different locations.

\section{Predicting what species may become invasive if introduced}

Invasive species are not limited to certain taxonomic groups or particular life/growth forms (Rejmánek and Richardson 1996; Pysek 1998). However, it may nevertheless be possible to predict what species, once introduced, are likely to become invasive. Reliable predictions are always difficult because many of the most aggressive invasives are introduced to the new continents either intentionally, largely for economic or ecological purposes, or accidentally through trade, transportation, or other means (see Goodwin et al. 1999). Better understanding of the roles of these pathways will certainly be needed. The composition of the regional flora is also important. For example, an initial analysis of trans-Pacific invasive plants shows that, proportionally, more woody species are among the most invasive plants introduced from eastern Asia to North America than among the species introduced from North America to eastern Asia (Guo 2002). The difference could simply reflect the fact that eastern Asia has more woody species than North America (Guo and Ricklefs 2000) or more woody ornamental plants have been introduced from eastern Asia to North America (W. Gregg, personal communications).

What are the similarities and differences in genetics, life history/morphological traits, dispersal mechanisms, and polyploidy levels (different polyploidy levels of the same species may show different invasiveness) of neo-disjunct species (Cadotte and Lovett-Doust 2001)? We predict that although species would show highly individualistic responses to the new environments (i.e., some morphological and life history traits of certain species may have diverged in the history of introduction, spread, and isolation), the most successful invasives may show greater genetic/phenotypic variation and adaptive flexibility. Future changes in land use activities and patterns among continents may further facilitate genetic/morphological divergence.

In order to identify the mechanisms of species invasiveness and to predict what species may become invasive, several studies have compared exotics with natives in the same floras yet little 
generalization has been observed (see Rejmánek 1996). A better way to reach this goal could be to (1) compare the invasives with all other introduced species (Figure 2), particularly those from the same source region (Kolar and Lodge 2001), and (2) compare established exotics with those which failed to persist after introduction (where known). Because most exotics do not become invasive, including all exotics in comparisons with natives might, in fact, obscure mechanisms that promote invasiveness. A practical issue is how we define "invasiveness," which seems to change with time and location. Unlike the term "exotic", which is relatively clearly defined (i.e., all species introduced to a specific region due to human activities), "invasive" usually defines relative rather than absolute qualities and may largely reflect the degree of ecological and/or economic damage. For example, early reports mentioned the "tens rule" (Williamson 1996; Kolar and Lodge 2001), which states that about $10 \%$ of introduced species become established, and $10 \%$ of those become invasive; however, this rule is not based on a rigorous definition of the term "invasive" (Figure 2).

Species vary greatly in adaptive genetic and morphological flexibility and resistance to environmental change or genetic stability. Some species change little genetically over millions of years while others undergo genetic restructuring in decades. For example, Tsutsui et al. (2000) showed how a genetic bottleneck in an introduced species (reduced genetic diversity relative to the native range) can lead to widespread ecological success. A review by Guo and Ricklefs

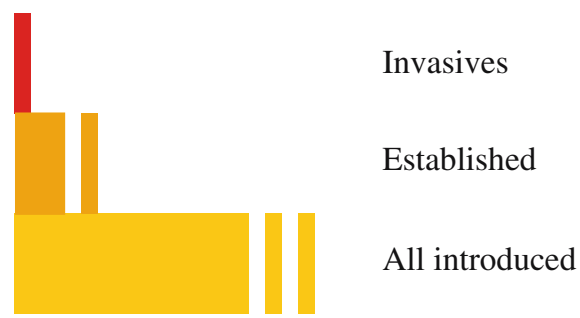

Figure 2. Categories proposed for comparative studies and the relative proportions of invasives, established, and introduced species based on Williamson's (1996) "tens rule". The actual proportion of invasives to established or introduced can be highly variable from continent to continent or from region to region. The relative values of these three categories in a particular habitat might be a good indicator of invasibility.
(2000) revealed that the ecological distributions of many woody paleo-disjunct taxa have changed little, implying little genetic change, since separation, while other studies provide opposite results for many herbaceous taxa, especially invasives. For example, Meekins et al. (2001) detected significant differences in genetic structure within and among populations and between native and introduced ranges for Alliaria petiolata, introduced to North America from Europe 125-years ago.

It is possible that some introduced species intrinsically have high invasiveness, but because of the presence of natural enemies or lack of widespread habitat disturbance in their native ranges, they have little opportunity to exploit such potentials. Once such species are introduced to new environments, they can become highly invasive. Because many invasives, once established, can quickly colonize habitats, the new environments can greatly modify the species' morphology and genetic structure. For example, polyploidy levels of a species can change dramatically after introduction and may sometimes result in new species (e.g., by adaptation, hybridization). This might not happen in their native regions where their ranges are relatively stable.

Many invasive species are successful also because they have high tolerance-levels, high fecundity, and rapid growth rates (e.g., Siemann and Rogers 2003). The probability of success of an invasive species may increase when environmental similarities exist between source and target areas. Nevertheless, various biotic and environmental factors are capable of limiting the success of even the most aggressive invasives. For example, cold temperatures reduce germination of Chinese tallow (Sapium sebiferum) and the plant is unable to survive periods of prolonged subfreezing temperatures (Bruce et al. 1997). Elevated soil salinity impaired the success of several invasive species (Barrileaux and Grace 2000). Habitat size, shape, structure (species richness and composition), proximity to other habitats, disturbance regimes (i.e., area, magnitude, frequency, natural or human-caused), and history on each continent also are known to affect a species' invasiveness.

Early studies have compared life history/morphology features (Bøhn et al. 2004), including 
plant size (Thebaud and Simberloff 2001), life/ growth form, life span, degree of woodiness, leaf morphology/anatomy (e.g., size, shape), dispersal mode, reproductive traits (e.g., seed size and number, dispersal mechanism, pollination, and mating system), and photosynthetic pathway (e.g., Thebaud and Simberloff 2000). Life/growth forms, number of flowers, and reproductive modes may shift through genetic/morphological adaptation, mutation, hybridization, cross-pollination, and habitat modification (e.g., Eupatorium adenophorum, introduced from Central America to China; Sun et al. 2004). However, despite these great efforts, few generalizations or consensuses have been reached (but see Rejmánek and Richardson 1996).

\section{Tracing the source population and invasion pathways}

Molecular techniques have greatly improved our ability to identify original source populations within the native ranges of invasive species, especially in accidental introductions, and the founding population in the introduced ranges (i.e., where the population starts to spread, e.g., botanical gardens). Such information is critical for identifying the invasion pathways and testing whether and/or how much the genetic structure of a species has changed since introduction. Phylogenetic hypotheses can be constructed from DNA sequencing of native and introduced populations for such purpose (e.g., Bond et al. 2002; Cox 2004).

The two- (or multi-) way traffic that characterizes biotic invasion will lead to higher similarity in ecological communities among continents in the future (Sax et al. 2002) and it is possible that many introduced species will be re-introduced back to their native ranges or continents. Such species may become harmful as back-invaders if they have been genetically and morphologically modified in their introduced ranges.

\section{Eco-functions of invasives in both native and introduced habitats}

What are the biological and ecosystem functions of alien taxa in local communities? We may predict that the functional roles of the invading taxa would vary because their relative dominance in local communities, in terms of biomass or cover, could change dramatically with climate, ecological disturbance, or genetic change. For example, kudzu (Pueraria lobata) was introduced to the United States from Japan in 1876 as an effective soil erosion control agent and ornamental plant, but nearly a century passed before the species was recognized as an invasive weed. The U.S. Department of Agriculture (USDA) declared kudzu a noxious weed in 1970 (USDAAgricultural Research Service 1971).

Exotics are likely to have different effects on, and functions in, ecosystems with native and introduced ranges and the effects are likely to vary with changing land use and climate. While many studies have examined the effects of invasives on introduced habitats, little is known about the ecosystem functions of these species in their native ranges.

\section{Distribution, species' borders, and niche-based modeling}

What are the factors that limit distribution and abundance of exotic species in their native ranges? These factors would likely be highly speciesspecific and could be biological, abiotic, or both (Brown 1989). Biological factors include pollinators, natural enemies, competitors, predators, reproductive modes, dispersal mechanisms, and behavioral performance. Abiotic factors include climate, soil, light, proximity, and disturbance regimes. Another factor that has been neglected could be the human use of the species in the native ranges for economic or medical purposes. Exotic species in target areas may also show different distribution patterns from their native ranges because of biotic factors that differentially limit their distributions and genetic changes after introduction. A recent study showed that dispersal by birds contributes to the invasiveness of Chinese tallow tree (Sapium sebiferum) in the United States (Renne et al. 2002). However, because the species has not been investigated in its native habitats, it remains unclear whether this dispersal mechanism occurs in the native range. 
Monitoring and comparing the boundary dynamics of both native and invaded ranges of invasives could be very informative, as a species' boundary is the most sensitive indicator of species expansion or contraction in response to environmental changes and species interactions (Hoffmann and Blows 1994; Guo et al. 2005). The boundary dynamics should be examined in three dimensions (compass directions and upper/ lower elevational limits) because each edge of the distribution might be controlled by different factors and/or at different levels. For example, the northern and southern boundaries may be mainly limited by temperature while the western/eastern boundaries may be limited by mountain ranges, soil, and/or water availability. Factors to be examined along boundaries of a species may include life history, seed banks, vegetative propagation, competition, soil, water, and other related factors that might be critical in controlling the exotic species' boundaries and in scaling from small patches within the range to the whole invaded range.

The potential for invasion may increase when climatic and soil conditions are similar for the native and target environments (Brown 1989). Therefore, exotic species are likely to invade ecosystems in close proximity to their currently established regions, and habitats elsewhere which are similar to their native habitats. In general, comparative methods may be used to determine whether certain characteristics (e.g., life form, dispersal mechanisms) can be used to predict which species are likely to become intercontinental invasives. After identifying the limiting factors and mapping the ecological features in an invasive's native region, we can identify and map the potential suitable habitats on the target continent with a high probability of future invasion. Cautions are needed when using niche-based modeling (Peterson and Vieglais 2001), however, because: (1) in many cases, distribution of invasives is at least partially controlled by biotic factors such as competition, predation, pollination, and dispersal, not purely physical factors such as climate, soils; and (2) in introduced ranges, the distribution of invasives is most commonly associated with human disturbances. For instance, if a site were not disturbed, it would be difficult for other species (including both native and exotic invasives) to invade ("preemption hypothesis"; Drake 1991).

In general, the exotics with broad distribution on the native continents should also have broad distributions on the introduced continents when enough time is given (e.g., McGlynn 1999; Figures 3 and 4), although exceptions may also exist. In the trans-Pacific case, a special factor in comparing distribution between native and exotic ranges is the role of landform or mountain ranges. That is, most major mountain ranges are latitudinal in eastern Asia but longitudinal in North America. This difference in landform orientation between eastern Asia and North America may influence the shapes of species' distribution ranges and the directions of species migration or spread under the effects of climatic changes.

\section{Methodology issues}

Molecular data have been widely used to trace the history, pathways, and spread of a species following introduction or isolation (Novak and Mack 2001). Other techniques such as stable isotope analysis (e.g., Zanden et al. 1999), simulation modeling (Higgins et al. 1996), bio(eco)informatics, remote sensing, and GIS are also increasingly used in studying biological invasions, especially for identifying the source populations of species introduction, tracing the invasion history, and

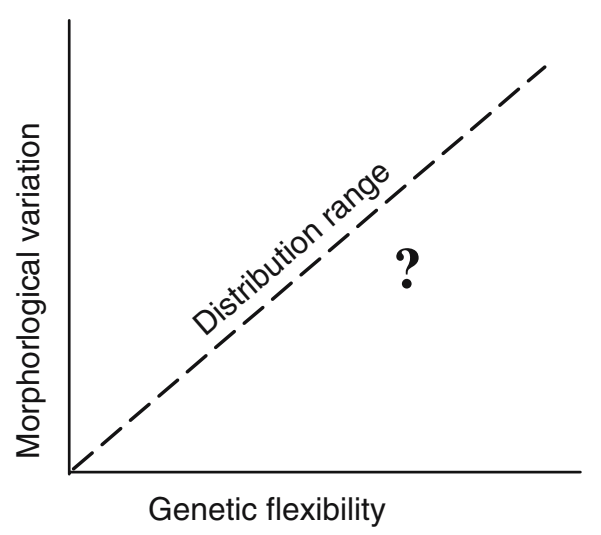

Figure 3. Hypothetical relationships among genetics, morphology, and distribution. It would be reasonable to assume that species with high genetic variation may also have greater variation in morphology, and both factors are likely influenced by the size of distribution ranges. 


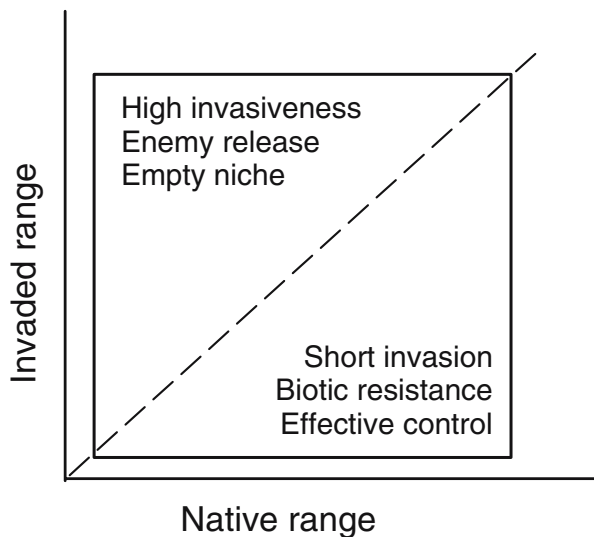

Figure 4. The distribution of exotics in native ranges may be used to predict the (future) distribution in exotic ranges. The position of a particular species in the graph may be determined by multiple factors as discussed in this article (e.g., time, rapid genetic variation and evolution, interspecies facilitation, mutualisms).

predicting the spread of invasions. These techniques are especially useful in the studies of intercontinental biotic invasions.

Botanical gardens and zoos can serve as candidate sites for early identification of potentially harmful invaders (for instance, by identifying the plant and animal species and pathogens that damage introduced plants, we can find indications of what species should not be introduced to other parts of the world; Dosmann and Del Tredici 2003). Herbarium and museum records are valuable for tracking the location of invasive species from their introduction through subsequent spread. We also have much to learn from agricultural systems or practices in which different crops, either in monoculture or mixed plantings, may show various levels of resistance to invasive weedy species.

To attain the objectives of the intercontinental comparative studies, for both native and introduced ranges, we can (1) build a database of information on life history, distribution, and ecology of focal species (Ricciard et al. 2000), (2) examine the history of invasions (time and location), (3) determine required landscape and biotic parameters from remote sensing and/or existing geospatial databases in a mapping context for both continents, and (4) map potential distributions or invasion areas on each continent based on the above information (e.g., Peterson and Vieglais 2001). Comparison of distribution pat- terns between native and introduced ranges may offer significant clues regarding where, in which direction, and at what rate an introduced species might spread (Figure 4).

The outcome of a comparison depends on what is included in the comparison. For example, we may compare plants from different categories separately, rather than combining in the same study invasives (subject to definition), all established exotics, and all introduced species (including both established and locally extinct; Figure 2). Other useful comparison may be made between congeners or sister species, i.e., one invasive and one not invasive. One unexplored but potentially insightful area could be to compare the function, distribution, and ecosystem effects of selected invasives on different continents from a common source region. For example, many invasives from Europe have invaded both eastern Asia and North America (e.g. Avena fatua, Daucus carota, Lolium temulentum, Senecio vulgaris, Ulex europaeus). Comparative studies of such species, especially those including experimental manipulations in both Asia and North America, can be highly useful (Blossey and Nötzold 1995; Losos et al. 2001; Siemann and Rogers 2003).

\section{Synthesis and intercontinental collaborations}

As awareness of the impacts of biological invasions increases, efforts are being made to investigate the mechanisms, pathways, rates, and magnitudes of species exchanges among continents. As such assessments progress, our ability to predict the future trends of biological invasion and to better manage our ecosystems so as to avoid future deleterious consequences will improve. While there are many sources of information on invasive species, they are largely independent of each other, of variable quality, and complex, making interpretation difficult (Pimm 1987). This has hampered research, treatment, and control of both newly arrived and established invasive species (Higgins et al. 1996; Bruce et al. 1997).

The ultimate scenario is yet to be fully realized: ecosystems around the globe will become increasingly similar due to intercontinental biotic invasions (Lockwood and McKinney 2001). Such biohomogenization, in turn, makes the possibility of 
establishment and success of invaders even higher. Without coordinated efforts to curb this process, it will go on until the most aggressive invaders occur everywhere that is ecologically suitable and many natives or even less-competitive exotics have been displaced or eliminated. Recent development of new molecular and isotope techniques, together with the rapid expansion in the applications of simulation modeling and GIS/remote sensing technologies, present innovative research opportunities. Synthesis of descriptions of invasive species in both native and target habitats as well as recent research results on molecular, chromosomal, phylogenetic, and biogeographic factors can help reduce global biotic invasions.

In short, early identification of invasive species and a better understanding of the limiting factors in their native habitats are critical for effective biological control and ecosystem management in invaded habitats. Biological invasion often involves global processes. Therefore, international cooperation is needed more than ever. Research on trans-Pacific biological invasions provides a good example. Effective communication and collaborations are needed to help ecologists and policy makers on each continent to balance their efforts in establishing standards, sharing information on invasive species, and exploring newly developed methodologies to better predict, track, and control invasion processes.

\section{Acknowledgements}

This article is based on a presentation during the Beijing International Symposium on Biological Invasions: Species Exchanges between Eastern Asia and North America (June 8-11, 2004). I thank T. Albright, W. Gregg, B. Hanson, D. Larson, S. Miao, R. Ricklefs, D. Sax, Y. Xie, Z. Zhu and many other individuals for communications and discussions on related issues. This work was supported by the U.S. Geological Survey.

\section{References}

Barrilleaux TC and Grace JB (2000) Growth and invasive potential of Sapium sebiferum (Euphorbiaceae) within the coastal prairie region: the effects of soil and moisture regime. American Journal of Botany 87: 1099-1106
Biggins DE and Kosoy MY (2001) Influences of introduced plague on North American mammals: implications from ecology of plague in Asia. Journal of Mammalogy 82: 906-916

Blossey B and Nötzold R (1995) Evolution of increased competitive ability in invasive nonindigenous plants: a hypothesis. Journal of Ecology 83: 887-889

Bøhn T, Sandlund T, Amundsen PA and Primicerio R (2004) Rapidly changing life history during invasion. Oikos 106: 138-150

Bond JM, Veenendaal EM, Hornby DD and Gray AJ (2002) Looking for progenitors: a molecular approach to finding the origins of an invasive weed. Biological Invasions 4: 349-357

Brown JH (1989) Patterns, modes and extents of invasions by vertebrates. In: Drake JA, Mooney HA, Castri Fdi, Groves RH, Kruger FJ, Rejmanek $M$ and Williamson $M$ (eds) Ecology of Biological Invasions: A Global Perspective, pp 85-109. Wiley, Chichester

Bruce KA, Cameron GN, Harcombe PA and Jubinsky G (1997) Introduction, impact on native habitats and management of a woody invader, the Chinese tallow tree, Sapium sebiferum (L.) Roxb. Natural Areas Journal 17: 255-260

Cadotte MW and Lovett-Doust J (2001) Ecological and taxonomic differences between native and introduced plants of southwestern Ontario. Ecoscience 8: 230-238

Callaway RM and Aschehoug ET (2000) Invasive plants versus their new and old neighbors: a mechanism for exotic invasion. Science 290: 521-523

Cox GW (2004) Alien Species and Evolution. Island Press, Washington (DC), 337

diCastri F (1989) History of biological invasions with special emphasis on the Old World. In: Drake JA, Mooney HA, Castri Fdi, Groves RH, Kruger FJ, Rejmanek $M$ and Williamson M (eds) Ecology of Biological Invasions: A Global Perspective, pp 1-30. Wiley, Chichester

Dosmann M and Del Tredici P (2003) Plant introduction, distribution, and survival: a case study of the 1980 SinoAmerican botanical expedition. BioScience 53: 588-597

Drake JA (1991) Community-assembly mechanics and the structure of an experimental species ensemble. American Naturalist 137: 1-26

Goodwin BJ, McAllister AJ and Fahrig L (1999) Predicting invasiveness of plant species based on biological information. Conservation Biology 13: 422-426

Guo Q (2002) Perspectives on trans-Pacific biological invasions. Acta Phytoecologica Sinica 26: 724-730

Guo Q and Ricklefs RE (2000) Species richness in plant genera disjunct between temperate eastern Asia and North America. Botanical Journal of the Linnean Society 134: 401-423

Guo Q, Taper ML, Schoenberger M and Brandl J (2005) Spatial-temporal population dynamics across species' range: from center to margin. Oikos 108: 47-57

Hänfling B and Kollmann J (2002) An evolutionary perspective of biological invasions. Trends in Ecology and Evolution 17: 545-546

Hierro JL, Maron JL and Callaway R (2005) A biogeographic approach to plant invasions: the importance of studying exotics in their introduced and native range. Journal of Ecology 93: 5-15

Higgins SI, Richardson DM and Cowling RM (1996) Modeling invasive plant spread: the role of plant-environment interactions and model structure. Ecology 77: 2043-2054 
Hoffmann AA and Blows MW (1994) Species borders: ecological and evolutionary perspectives. Trends in Ecology and Evolution 9: 223-227

Kitayama K and Mueller-Dombois D (1995) Biological invasion on an oceanic island mountain: do alien plant species have wider ecological ranges than native species?. Journal of Vegetation Science 6: 667-674

Klironomos JH (2002) Feedback with soil biota contributes to plant rarity and invasiveness in communities. Nature 417: 67-70

Kolar CS and Lodge DM (2001) Progress in invasion biology predicting invaders. Trends in Ecology and Evolution 16: 199-204

Kowarik I (1995) Time lags in biological invasions with regard to the success and failure of alien species. In: Pyšek P, Prach $\mathrm{K}$, Rejmánek $\mathrm{M}$ and Wade $\mathrm{M}$ (eds) Plant Invasions General Aspects and Special Problems, pp 15-38. SPB Academic Publishing, Amsterdam

Livdahl TP and Willey MS (1991) Prospects for an invasion: competition between Aedes albopictus and native Aedes triseriatus. Science 253: 189-191

Lockwood JL and McKinney ML eds (2001) Biotic Homogenization. Kluwer Academic/Plenum Publishers, New York,

Lodge DM (1993) Biological invasions: lessons for ecology. Trends in Ecology and Evolution 8: 133-137

Losos JB, Schoener TB, Warheit KI and Creer D (2001) Experimental studies of adaptive differentiation in Bahamian Anolis lizards. Genetica 112-113: 399-415

Mack RN, Simberloff D, Lonsdale WM, Evans H, Clout M and Bazzaz FA (2000) Biotic invasions: causes, epidemiology, global consequences, and control. Ecological Applications 10: 689-710

McGlynn TP (1999) The worldwide transfer of ants: geographical distribution and ecological invasions. Journal of Biogeography 26: 535-548

Meekins JF, Ballard HE and McCarthy BC (2001) Genetic variation and molecular biogeography of a North American invasive plant species (Alliaria petiolata, Brassicaceae). International Journal of Plant Sciences 162: 161-169

Memmott J, Fowler SV, Paynter Q, Sheppard AW and Syrett P (2000) The invertebrate fauna on broom, Cytisus scoparius, in two native and two exotic habitats. Acta Oecologica 21:213-222

Mitchell CE and Power AG (2003) Release of invasive plants from fungal and viral pathogens. Nature 421: 625-627

Moron JL and Vilá M (2001) Do herbivores affect plant invasion? Evidence for the natural enemies and biotic resistance hypotheses. Oikos 95: 363-373

Novak SJ and Mack RN (2001) Tracing plant introduction and spread: genetic evidence from Bromus tectorum (cheatgrass). BioScience 51: 114-122

Pappert RA, Hamrick JL and Donovan LA (2000) Genetic variation in Pueraria lobota (Fabaceae), an introduced, clonal, invasive plant of the southeastern United States. American Journal of Botany 87: 1240-1245

Peterson AT and Vieglais DA (2001) Predicting species invasions using ecological niche modeling: new approaches from bioinformatics attack a pressing problem. BioScience 51: 363-371

Pimm SL (1987) Determining the effects of introduced species. Trends in Ecology and Evolution 2: 106-108
Pysek P (1998) Is there a taxonomic pattern to plant invasions? Oikos 82: 282-294

Qian H and Ricklefs RE (2004) Geographic distributions and ecological conservatism of disjunct genera of vascular plants in eastern Asia and eastern North America. Journal of Ecology 92: 253-265

Rejmánek M and Richardson DM (1996) What attributes makes some plant species more invasive. Ecology 77: 1655-1661

Renne IJ, Barrow WC, Randall LAJ and Bridges WC (2002) Generalized avian dispersal syndrome contributes to Chinese tallow tree (Sapium sebiferum, Euphorbiaceae) invasiveness. Diversity and Distributions 8: 285-295

Rhymer JM and Simberloff D (1996) Extinction by hybridization and introgression. Annual Review of Ecology and Systematics 27: 83-109

Ricciard A, Steiner WWM, Mack RN and Simberloff D (2000) Toward a global information system for invasive species. BioScience 50: 239-244

Ricklefs RE and Latham RE (1992) Intercontinental correlation of geographical ranges suggests stasis in ecological traits of relict genera of temperate perennial herbs. American Naturalist 139: 1305-1321

Sax DF, Gaines SD and Brown JH (2002) Species invasion exceeds extinction on islands worldwide: a comparative study of plants and birds. American Naturalist 160: 766-783

Sher AA and Marshall DL (2003) Competition between native and exotic floodplain tree species across water regimes and soil textures. American Journal of Botany 90: 413-422

Siemann E and Rogers WE (2001) Genetic differences in growth of an invasive tree species. Ecology Letters 4: 514-518

Siemann E and Rogers WE (2003) Increased competitive ability of an invasive tree may be limited by an invasive beetle. Ecological Applications 13: 1503-1507

Simberloff D and Von Holle B (1999) Positive interactions of nonindigenous species: invasional meltdown?. Biological Invasions 1: 21-32

Sun XY, Lu ZH and Sang WG (2004) Review on studies of Eupatorium adenophorum - an important invasive species in China. Journal of Forestry Research 15: 319-322

Thebaud C and Simberloff D (2000) Are plants really larger in their introduced ranges?. American Naturalist 157: 231-236

Torchin ME, Lafferty KD and Kuris AM (2001) Release from parasites as natural enemies: increased performance of a globally introduced marine crab. Biological Invasions 3: 333-345

Tsutsui ND, Suarez AV, Holway DA and Case TJ (2000) Reduced genetic variation and the success of an invasive species. Proceedings of the National Academy of Sciences of the USA 97: 5948-5953

USDA-Agricultural Research Service (1971) Common weeds of the United States. Dover Publications, Inc., New York

Vermeij GJ (1991) When biotas meet: understanding biotic interchange. Science 253: 1099-1104

Williamson M (1996) Biological Invasions. Chapman and Hall, London

Zanden MJV, Casselman JM and Rasmussen JB (1999) Stable isotope evidence for the food web consequences of species invasions in lakes. Nature 401: 464-467 